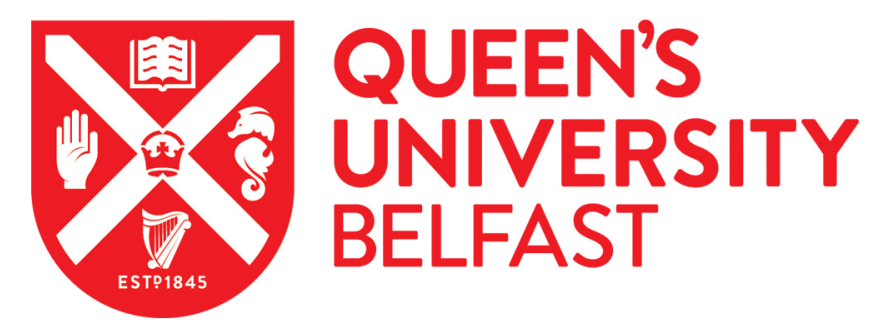

\title{
Carotid artery intimal medial thickness and carotid artery plaques in hypertensive patients with non-arteritic anterior ischaemic optic
} \section{neuropathy}

Zhu, W., Chen, T., Jin, L., Wang, H., Yoa, F., Wang, C., Wang, Q., \& Congdon, N. (2017). Carotid artery intimal medial thickness and carotid artery plaques in hypertensive patients with non-arteritic anterior ischaemic optic neuropathy. Graefe's Archive for Clinical and Experimental Ophthalmology, 255(10), 2037-2043. https://doi.org/10.1007/s00417-017-3744-4

\section{Published in:}

Graefe's Archive for Clinical and Experimental Ophthalmology

\section{Document Version:}

Peer reviewed version

Queen's University Belfast - Research Portal:

Link to publication record in Queen's University Belfast Research Portal

\footnotetext{
Publisher rights

(C) 2017 Springer International Publishing AG. This work is made available online in accordance with the publisher's policies. Please refer to any applicable terms of use of the publisher.
}

\section{General rights}

Copyright for the publications made accessible via the Queen's University Belfast Research Portal is retained by the author(s) and / or other copyright owners and it is a condition of accessing these publications that users recognise and abide by the legal requirements associated with these rights.

Take down policy

The Research Portal is Queen's institutional repository that provides access to Queen's research output. Every effort has been made to ensure that content in the Research Portal does not infringe any person's rights, or applicable UK laws. If you discover content in the

Research Portal that you believe breaches copyright or violates any law, please contact openaccess@qub.ac.uk. 


\section{Graefe's Archive for Clinical and Experimental Ophthalmology Carotid artery intimal medial thickness and carotid artery plaques in hypertensive patients with non-arteritic anterior ischaemic optic neuropathy \\ --Manuscript Draft--}

Manuscript Number:

Full Title:

Keywords:

Corresponding Author:
Article Type:

GRAE-D-17-00406R1

Carotid artery intimal medial thickness and carotid artery plaques in hypertensive patients with non-arteritic anterior ischaemic optic neuropathy

Neurophthalmology

Non-arteritic anterior ischaemic optic neuropathy ; Intimal medial thickness ; Carotid artery plaque; Doppler sonography

Nathan Congdon, M.D.

Sun Yat-Sen University Zhongshan Ophthalmic Center CHINA

Corresponding Author Secondary Information:

Corresponding Author's Institution:

Sun Yat-Sen University Zhongshan Ophthalmic Center

\section{Corresponding Author's Secondary} Institution:

First Author:

Wenhui Zhu

First Author Secondary Information:

Order of Authors:

Wenhui Zhu

Tingting Chen

Ling Jin

Haoyu Wang

Fengjuan Yao

Congyao Wang

Qi Wang

Nathan Congdon, M.D.

\section{Order of Authors Secondary Information:}

Funding Information:

The Department of Science and
Technology of Guangdong Province,
China
(2014A020212578)

M.D. Wenhui Zhu

Abstract:

Purpose: To assess the correlation of carotid artery intimal medial thickness (C-IMT) and carotid artery plaque score (CPS) of the common carotid artery with non-arteritic anterior ischemic optic neuropathy (NAION) in hypertensive patients.

Methods: This case-control study recruited 192 subjects. 48 patients had NAION with systemic hypertension, 46 had hypertension without visual complaints and 98 were normal controls. C-IMT and common carotid arterial plaque were measured by highresolution vascular ultrasonography.

Results: High-density lipoprotein $(\mathrm{HDL})$ in patients with NAION $(1.24 \pm 0.31)$ was significantly lower than that of the Hypertensive group $(1.39 \pm 0.30, P=0.034)$. The $\mathrm{C}$ IMT in the affected side of patients with NAION $(1.00 \pm 0.23)$ was significantly increased compared to the unaffected side $(0.83 \pm 0.19, P<0.001)$, the Hypertensive group $(0.83 \pm 0.17, P<0.001)$ and the Normal group $(0.69 \pm 0.16, P<0.001)$. The presence of carotid artery plaque was more frequent in the patients with NAION, compared to either the Hypertensive group $(P=0.001)$ or the Normal group $(P<0.001)$. By multiple regression analysis, lower high-density lipoprotein $(\mathrm{HDL})(\mathrm{P}=0.009)$, thicker $\mathrm{C}-\mathrm{IMT}$ $(P=0.002), C P S$ Grade $=1(P=0.028)$ and Grade $=2(P=0.005)$ were associated with 
increased NAION risk, when the NAION group compared with the Hypertensive group $(\mathrm{OR}>1.0)$. Systolic blood pressure $(P=0.001)$, thicker $C-\mathrm{IMT}(\mathrm{P}<0.001)$, CPS Grade $=1$ $(P=0.006)$, Grade $=2(P=0.002)$ and Grade $=3(P=0.015)$ were associated with increased NAION risk, when the NAION group compared with the Normal group $(\mathrm{OR}>1.0)$.

Conclusions: C-IMT and CPS were associated with NAION in hypertensive patients, suggesting that NAION might be associated with carotid artery atherosclerosis. This association may be due to similar pathological changes of the inner vascular walls in the carotid artery and the arteries supplying the optic nerve head. 


\section{Dear Editor,}

Non-arteritic anterior ischaemic optic neuropathy (NAION) is a common reason for sudden optic nerve-related visual loss in the middle-aged and elderly population. Although some specific aetiologies of NAION have been suggested, the exact causal mechanism is still unclear. Our previous study found the intima-media thickness of the common carotid artery (C-IMT) was greater on the side affected by NAION compared to normal controls but the relationship between artery atherosclerosis and NAION still remains unclear. Our new study measured C-IMT and thickness of carotid artery plaque using high-resolution ultrasonography; these two parameters are widely used to diagnose atherosclerosis. This study found that C-IMT and carotid artery plaque were associated with NAION in hypertensive patients with NAION, suggesting that NAION might be associated with carotid artery atherosclerosis.

Graefe's Archive for Clinical and Experimental Ophthalmology is one of the most widely read journals in ophthalmology. We hope that you and your reviewers will agree that this manuscript will be of interest to the global readership.

Best regards,

Nathan Congdon

PI 
Authorship Form: Graefes Archive for Clinical and Experimental Ophthalmology

Title:- Carotid artery intimal medial thickness and carotid artery plaques in hypertensive patients

1. Nathan Cangdon horeby confirm that alt named authors meot the ICM.JE

(corresponding author)

requirement of authorship and meet all three criterla as mentioned below.

1) substantial contributions to conception and dosign, or acquisition of data, or analysis and interprotation of data;

2) drafting the article or rovising it critically for important intellectual content; and

3) final approval of the version to be publishod.

Authors should meet constitions 1,2 , ard 3 .

signed: Nathan Congdon

signed: Hasuw Wang 2 是多

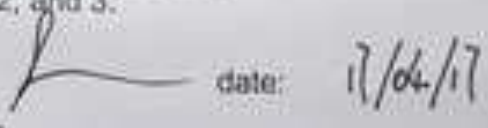

scgned: Tingting chen $B$ itvitut

signed: Congloo Wang in a है

signed: Lingim $123 \sqrt{2}$

signed: Yooforg Juan Xeposes

signediWay 质哺

signed: Wahkat the tivy

signed:

date: $14 / 04 / 17$

date: $161.4 / 17$

date: $16 / 04 / 17$

date: $16 / 04 / 0$ ?

dates $16 / 04 / 17$

date: $77 / 04 / 17$

date: $17 / 09 / 17$

"First signature should be of corresponding author

The acknowledgment section includes contributors who provided purely technical help, writing assistance, or a department chair who provided only general support. Medical Writers; Financial and material support should also be acknowledged.

Geoups of persons who have contrhused materially to the paper but whose contributions do not justry authorship may be listed under a heading such as 'clinical investigators' or 'participating investigators;' and their function or contribution should be described-for exarnple, 'Served as scientific advisors. "critically reviownd the study proposal, "bollected dats;' or 'provided and carned for study pationsts."

I confirm that this paper is not being submitted simultaneously elsewhere.

signed: Nathan Congden daso: 17/04/17

(corresponding suthor) 
Dear Dr. Joussen,

Thank you very much for your advice. We have revised the paper by addressing the comments raised by the reviewer, and the amendments are highlighted in red in the revised manuscript. We would like to thank the reviewers for their constructive and positive comments. Please see our response below.

Response to Reviewer \#1:

Reviewer \#1: A very interesting paper about AION and an association between the process of AION and the disease of the internal vessel wall. Because there is a significant correlation between the anatomy of the optic nerve head and rheological disorders in the pathogenesis of AION, you should avoid the impression, that a disease of the internal vessel wall of the carotid artery tributes significantly to AION. You stated correctly, that: "suggests the possibility of similar pathological changes in the context of intimal injury, thickening of muscular elastic layer, stenosis, increased vascular tone and impaired regulation of blood flow in the arteries supplying the optic disc.

1-1. You should include this statement in the abstract at the end of conclusion: )Proposal:

$\cdots$. This association may be due to the same pathological changes of the inner vessel walls in carotid artery and the vessels supplying the optic nerve head.

Thank you for your comment. Correction has been made in the revised version (please refer to conclusion of the abstract).

1-2. The question you might discuss is the relevance of C-IMT in the routine evaluation of AION. Is there a need for this evaluation?

Screening C-IMT and CPS with carotid artery ultrasound might be useful in evaluation of potential NAION, in particular those with high risk for carotid artery atherosclerosis. We have added this to the conclusion.

1-3. Page 9 line 28- 34: Can you explain shortly, why you have this directive for the examination for the inexperienced ophthalmologist?

It is routine practice for vascular ultrasound in our hospital in order to achieve more accurate and objective measurements.

1-4. Page 9 line 56-58: I do not understand the meaning of this statement.

C-IMT was measured in both common carotid arteries in each subject. The result of each control group was the average of bilateral measurements. Correction has been made in the revised version (Please refer to paragraph 5 in the Methods section).

1-5. Page 10 line 56-58: you do not really detect risk factors by statistic:

‥ was used to quantify the studied risk factors.

Thank you for your comment. Correction has been made in the revised version (please refer to the statistical methods paragraph). 
Response to Reviewer \#2:

Reviewer \#2: In "Carotid artery intimal medial thickness and carotid artery plaques in hypertensive patients with non-arteritic anterior ischaemic optic neuropathy" compared carotid intimal medial thickness (C-IMT) and carotid artery plaque score (CPS) measures in 48 patients with non-arteritic anterior ischaemic optic neuropathy (NAION), 46 hypertension normally sighted patients, and 96 healthy control subjects.

They found statistically significant higher C-IMT and CPS in group NAION than Hypertension and both shown higher values than controls.

The data is interesting, and the article is well written, but, although it seems reasonable that a vascular change found at carotid artery could be related to the risk of NAION, some aspects of the methodology should be better explained.

1. Methods seem to suggest that C-IMT and CPS were measured on the "ipisilateral carotid" for NAION group. Meaning the same side of the NAION eye. Please make it moreclear in the manuscript.

C-IMT measurement of each side of carotid artery was repeated three times and the average was obtained for analysis. The result of each NAION patient was reported separately as 1) the average of the affected side (ipsilateral to the eye affected by NAION) and the average of the unaffected side (contralateral to the eye affected by NAION). The result of each control group was the average of bilateral measurements. Correction has been made in the revised version (Please refer to paragraph 5 in the Methods section).

2. Measurements were performed 3 times and the greatest thickness was used. Why? Was the variability high?

We are very sorry this was a typing mistake. It should be 'Measurements were performed 3 times and the average thickness was used'. We have corrected this in the Methods. Each C-IMT measurement could be slightly variable due to noise; hence we averaged 3 repeated measurements. (Please refer to paragraph 5 in the Methods section).

3. Did the contra-lateral carotid suggest that these patients were at risk for developing NAION on the contralateral eye? Since patients have been included since 2011, authors should have data about it.

The C-IMT of the unaffected side of the NAION patients $(0.83 \pm 0.19)$ was not different from that of the hypertension group $(0.83 \pm 0.17, P=1.000)$, however, it was significantly higher compared to that of the healthy normal controls $(0.83 \pm 0.19$ vs. $0.69 \pm 0.16, P<0.001)$. In the absence of follow-up of the subjects, we do not know whether or not these contralateral eyes of the NAION patients were at risk for developing NAION. Further studies are needed to assess the change of carotid artery ultrasound findings as well as occurrence of NAION in the contralateral eye. We have clarified this in the revised manuscript (Please refer to paragraph 5 in the Discussion).

4. Did the contralateral carotid also show higher thickness and scores than the hypertension 
group?

The C-IMT of the unaffected side among NAION patients was not different from that of the Hypertensive group. We have added the C-IMT data of the contralateral carotid artery in paragraph 2 of the Results section and also Table 1. Since carotid artery plaque score in our study was determined by adding the CPS from each carotid artery, meaning only one CPS for each subject, there was no separate contralateral carotid score to compare with the hypertensive group.

5. Author could inform how many patients were taking aspirin?

No patients were taking aspirin and they had no history of cardiovascular or cerebrovascular disease. We have clarified this in the revised manuscript (Please refer to paragraph 1 in the Results).

6. As for the data presentation, it would be interesting to see examples ( 1 or 2 cases) of the C-IMT and CPS measurements in a US picture, and the counterpart ipsilateral NAION optic nerve photography.

We have added the US pictures and the fundus photographs of a typical NAION patient to the revised manuscript (Please refer to paragraph 3 in result and figure section).

Also some conclusions cannot be supported by these data.

7. The fact that the hypertensive group showed slightly higher HDL than NAION patients might indicate that HDL is a good signal, but it doesn't mean that this alone has a 'protective' effect against NAION.

Thank you for your comments. We have carefully revised the manuscript to reflect this point (Please refer to paragraph 4 in the Discussion). 


\section{Carotid artery intimal medial thickness and carotid artery plaques in hypertensive patients with non-arteritic anterior ischaemic optic neuropathy}

Wenhui Zhu, MD ${ }^{1,2^{*}}$, Tingting Chen, MD ${ }^{1,2^{*}}$, Ling Jin, MS ${ }^{1}$, Haoyu Wang, BSc ${ }^{3}$, Fengjuan Yao, MD, $\mathrm{PhD}^{4}$, Congyao Wang, $\mathrm{MD}^{1}$, Qi Wang, $\mathrm{BSc}^{2}$, Nathan Congdon, MD, MPH ${ }^{1.5}$

1. State Key Laboratory of Ophthalmology, Zhongshan Ophthalmic Center, Sun Yat-sen University, Guangzhou, China, 510060

2. Department of Ophthalmology, The First Affiliated Hospital of Sun Yat-sen University, Guangzhou, China, 510080

3. School of Medicine, University of Manchester, Oxford Road, Manchester, United Kingdom M13 9PT

4. Department of Ultrasound, The First Affiliated Hospital of Sun Yat-sen University, Guangzhou, China, 510080

5. Centre for Public Health, Queen’s University Belfast, Belfast BT12 6BJ, Northern Ireland

*Co-first authors

Corresponding author: Nathan Congdon,

Mailing address: State Key Laboratory of Ophthalmology, Zhongshan Ophthalmic Center, Sun Yat-sen University, 54 S. Xianlie Road, Guangzhou, People's Republic of China, 510060

E-mail: ncongdon1@gmail.com

Telephone: +86 (20) 87682342 


\begin{abstract}
Purpose: To assess the correlation of carotid artery intimal medial thickness (C-IMT) and carotid artery plaque score (CPS) of the common carotid artery with non-arteritic anterior ischemic optic neuropathy (NAION) in hypertensive patients.
\end{abstract}

Methods: This case-control study recruited 192 subjects. 48 patients had NAION with systemic hypertension, 46 had hypertension without visual complaints and 98 were normal controls. C-IMT and common carotid arterial plaque were measured by high-resolution vascular ultrasonography.

Results: High-density lipoprotein (HDL) in patients with NAION $(1.24 \pm 0.31)$ was significantly lower than that of the hypertension Hypertensive group $(1.39 \pm 0.30$, $\mathrm{P}=0.034)$. The C-IMT in the affected side of patients with NAION $(1.00 \pm 0.23)$ was significantly increased compared to the unaffected side $(0.83 \pm 0.19, \mathrm{P}<0.001)$, the hypertension- Hypertensiveen group $(0.83 \pm 0.17, \mathrm{P}<0.001)$ and the normal-Normal group $(0.69 \pm 0.16, \mathrm{P}<0.001)$. The presence of carotid artery plaque was more frequent in the patients with NAION, compared to either the hypertension-Hypertensiveen group $(\mathrm{P}=0.001)$ or the nermal-Normal group $(\mathrm{P}<0.001)$. By multiple regression analysis, lower high-density lipoprotein (HDL) ( $\mathrm{P}=0.009)$, thicker C-IMT $(\mathrm{P}=0.002)$, CPS Grade $=1(\mathrm{P}=0.028)$ and Grade $=2(\mathrm{P}=0.005)$ were associated with increased NAION risk, when the NAION group compared with the Hypertensive group $(\mathrm{OR}>1.0)$. Systolic blood pressure $(\mathrm{P}=0.001)$, thicker C-IMT $(\mathrm{P}<0.001)$, CPS Grade $=1(\mathrm{P}=0.006)$, Grade $=2(\mathrm{P}=0.002)$ and Grade $=3(\mathrm{P}=0.015)$ were associated with increased NAION risk, when the NAION group compared with the normal-Normal 
group (OR>1.0).

Conclusions: C-IMT and CPS were associated with NAION in hypertensive patients, suggesting that NAION might be associated with carotid artery atherosclerosis. This association may be due to similar pathological changes of the inner vascular walls in the carotid artery and the arteries supplying the optic nerve head.

Key words: Non-arteritic anterior ischaemic optic neuropathy; Intimal medial thickness; Carotid artery plaque; Doppler sonography 


\section{Introduction}

Non-arteritic anterior ischaemic optic neuropathy (NAION) is the commonest form of acute optic neuropathies occurring in the middle-aged and elderly population [1], with an estimated prevalence of 1 in 4,500 in Chinese population aged over 40 years according to the Beijing Eye Study [2]. Some specific aetiologies of NAION have been suggested, but the exact causal mechanism still remains unclear. NAION is widely believed to be a consequence of vascular insufficiency proceeding to ischaemia of the optic nerve head, and is characterized by acute, painless visual loss and visual field defects [3]. Many risk factors for NAION have been identified, including small, crowded discs and traditional cardiovascular risk factors (hypertension, diabetes mellitus, dyslipidemia, and coronary artery disease) [4-5]. Hypertension is the commonest vasculopathic risk factor for NAION patients, accounting for 47 to $49 \%$ of cases [6].

Sanjari et al using high-resolution ultrasonography revealed that the intima-media thickness of the common carotid artery (C-IMT) on the affected side of NAION was thicker than that of the contralateral healthy side [7], while our previous study found C-IMT was greater on the side affected by NAION compared to normal controls, but not different compared to the unaffected side of NAION patients [8].

Endothelium-dependent flow-mediated vasodilation (FMD) of the brachial artery is a 
validated, widely used and non-invasive measure in assessing overall endothelial function. Our previous study showed that dysfunctional endothelium (lower FMD) was associated with greater risk of NAION [9]. Dysfunctional endothelium may increase vascular tone and promote adhesion of monocytes and leucocytes as well as activation of platelets and formation of thrombus [10-11]. Grønholdt et al found a significant association between echolucent carotid artery plaque and embolic cerebrovascular accidents and suggested that the former could be used to predict the risk of developing stroke [12]. Kim et al reported in a case study that the presence of echolucent carotid artery plaque could be the embolic origin in causing NAION [13]. In addition, Leisser $\mathrm{C}$ found NAION patients had statistically significantly more frequent small plaques in the internal carotid artery [14]. However, the relationship between carotid artery plaque and NAION still remains unclear.

Our study was designed to assess C-IMT and carotid artery plaque of common carotid arteries in hypertensive patients with unilateral NAION and to evaluate their associations with NAION.

\section{Patients and Methods}

This study was approved by the Ethics Committee of Sun Yat-sen University, Guangzhou, China, written consent was provided by all study participants, and the tenets of the Declaration of Helsinki were followed throughout. 
Consecutive, consenting participants aged 36 to 79 years meeting the below inclusion criteria were recruited between March 2011 and September 2016 at Zhongshan Ophthalmic Centre (ZOC) and the First Affiliated Hospital of Sun Yat-sen University. Blood pressure, C-IMT, carotid artery plaques and fasting (> 8 hours) blood samples were obtained from these eligible patients.

Three patient groups were recruited including 1) NAION group (patients with both systemic hypertension [systolic blood pressure > $140 \mathrm{mmHg}$, diastolic blood pressure > $90 \mathrm{mmHg}$ or currently on antihypertensive medications] and unilateral NAION), 2) Hypertensive group (patients with systemic hypertension -and no visual complaints) and 3) Normal group (healthy volunteers who were normotensive, never used antihypertensive medications and had no family history of vascular disease, or personal history of visual problems). Patients in the Hypertensive group and Normal group experienced no acute visual loss or impaired visual function at the time of recruitment and were enrolled at First Affiliated Hospital of Sun Yat-sen University. Patients from the NAION group were recruited from both ZOC and First Affiliated Hospital of Sun Yat-sen University and participants from all three groups had a full ophthalmological assessment with slit-lamp biomicroscopy and dilated funduscopic examination by a 78-diopter lens.

Exclusion criteria included: current pregnancy; current or recent (last 5 years) history of smoking; history of cardiovascular or cerebrovascular disease; diabetes mellitus; 
dyslipidaemia; alcohol abuse; high erythrocyte sedimentation rate (ESR) or a history suspicious for giant cell arteritis.

NAION was defined clinically as an acute presentation with painless loss of visual acuity in one eye, accompanied by relative afferent pupillary defect, optic disc oedema, visual field defect on automated perimetry and/or early filling defect of the disc by fluorescein angiography (FFA) in the affected eye, without evidence of other neurological, systemic or relevant ocular disease. Blood pressure was checked in a sitting position after patients rested for 10 minutes; we obtained three 3 measures and the mean was calculated. All participants were asked to fast for at least 8 hours, not to drink coffee for at least 2 hours and to rest for 15 minutes prior to the ultrasound examination.

C-IMT was measured in both common carotid arteries $1 \mathrm{~cm}$ proximal to carotid artery bifurcation with a high-resolution vascular ultrasound probe $(5-12 \mathrm{MHz}, \mathrm{GE}$ VIVID7, USA) in longitudinal section, using B-mode. C-IMT was calculated from the distance between two echogenic lines represented by the lumen-intima interface and the media-adventitia of the arterial wall respectively. Each-C-IMT measurement of the ipsilaterateach side of carotid artery was repeated three times and the average-greatest carotid intima-media thickness was obtained for analysis. The result of each NAION patient was presented separately as 1) the average of the affected side (ipsilateral to 
the eye affected by NAION). The result for theof each control groups was the average of bilateral measurements.

Carotid artery plaque was measured using the same ultrasound probe and defined as a focal thickening that encroaches into the lumen by $0.5 \mathrm{~mm}$, by $50 \%$ of the surrounding C-IMT or by C-IMT of $>1.5 \mathrm{~mm}$ according to the European Mannheim consensus [15-16]. All the plaques with maximum thickness in one carotid artery were measured regardless of plaque length and then the sum of these measurements were used to calculate carotid artery plaque score (CPS) [17]. Total CPS was calculated by adding the CPS from each carotid artery. Carotid artery plaque score was standardised as below: score of 0 when no plaques; score of 1 when both of the bilateral plaques were $<2 \mathrm{~mm}$; score of 2 when plaque from one carotid artery was $\geq 2$ $\mathrm{mm}$ and the other was $<2 \mathrm{~mm}$; and score of 3 when plaques from both carotid arteries were $\geq 2 \mathrm{~mm}[18]$. All the ultrasound measurements were performed and reported by the same expert operator, who was masked to the subject's medical condition.

\section{Statistical methods}

Results were presented as mean \pm standard deviation (SD) for continuous data and frequency (proportion) for categorical data. One-way ANOVA for continuous variables, logistic regression for sex and ordinal logistic regression for CPS were used for comparing the NAION group with the Hypertensive and Normal groups, and the $\mathrm{P}$ 
values of multiple comparisons underwent Bonferroni correction. Multinomial logistic regression was used to detect quantify the studied risk factors on NAION with Hypertensive and Normal groups as reference groups. Variables with $\mathrm{P}<.05$ in simple regression were included in the multiple regression model. Statistical analyses were performed using a commercially available software package (Stata 13.1, StataCorp, College Station TX, USA). Two-sided $\mathrm{P}<.05$ was considered statistically significant for the main hypothesis.

\section{Results}

A total of 48, 46 and 98 patients were recruited in the NAION (mean [SD] age, 56.7 [11.9] years; 19 male [39.6\%]), Hypertensive (mean [SD] age, 56.5 [9.25] years; 24 male [52.2\%]) and Normal (mean [SD] age, 57.3 [10.9] years; 49 male [50.0\%]) groups respectively (Table 1 ). The mean duration for NAION was $12.2 \pm 3.6$ days and the mean interval between onset of NAION and variable measurements was $3.2 \pm 1.8$ days. Among 48 patients in the NAION group, $36(75 \%)$ were prescribed anti-hypertensive medications, which did not differ $(\mathrm{P}>0.999)$ from the proportion of patients who were receiving such medications in the Hypertensive group (34 of the 46 subjects [74\%]) (Data was not presented in table.)№ patients were taking aspirin in any of the three groups.

No significant differences were observed with regard to age and gender between these 
groups and no difference was found between the three groups from laboratory parameters (Table 1). The systolic blood pressure (SBP) was significantly higher among patients in NAION group $(135.6 \pm 16.3)$ compared to the Normal group (120.8 $\pm 10.0, \mathrm{P}<0.001)$; however, no difference was detected between the NAION group and the Hypertensive group $(134.8 \pm 15.7, \mathrm{P}=1.00)$ (Table 1). The C-IMT on the affected side of the patients with NAION (1.00 \pm 0.23$)$ was significantly higher compared to the unaffected side $(0.83 \pm 0.19, \mathrm{P}<0.001)$. This measurement was also significantly higher than that in the Hypertensive group $(0.83 \pm 0.17, \mathrm{P}<0.001)$ and in the Normal group $(0.69 \pm 0.16, \mathrm{P}<0.001)$. The $\mathrm{C}$-IMT of the unaffected side of NAION patients was not different from that of the Hypertensive group ( $\mathrm{P}=1.000)$, however, it was significantly higher compared to that of healthy normal subjects $(0.83 \pm 0.19$ vs . $0.69 \pm 0.16, \mathrm{P}<0.001)$. The CPS was more frequent in the patients with NAION, comparing to either the Hypertensive group $(\mathrm{P}=0.001)$ or the Normal group $(\mathrm{P}<0.001)$.

Figure 1 shows Doppler imaging and the ipsilateral fundus photographs of a typical patient with unilateral NAION, including the images of the bilateral C-IMT, carotid artery plaque of maximum thickness, and bilateral fundus photographs.

Table 2 presented the multiple regression analysis of potential risk factors for NAION group compared with Hypertensive and Normal groups. Our results showed that when comparing with Hypertension group, thicker C-IMT (OR, 28.4; 95\% CI, 1.74- 464.5, 


\begin{abstract}
$\mathrm{P}=0.002)$, the carotid artery plaques of grade $1(\mathrm{OR}, 3.78$; 95\% $\mathrm{CI}, 1.15-12.4, \mathrm{P}=0.028)$ and grade $2(\mathrm{OR}, 8.84 ; 95 \% \mathrm{CI}, 1.91-40.8, \mathrm{P}=0.005)$ were predictive for the development of NAION; whereas higher level of high-density lipoprotein (HDL) (OR, $0.11 ; 95 \% \mathrm{CI}, 0.02-0.58, \mathrm{P}=0.009)$ were associated with lower risk of NAION. While comparing with Normal group, higher SBP (OR, 1.07; 95\% CI, 1.03-1.12, $\mathrm{P}=0.001$ ), thicker C-IMT (OR, 2351.4; 95\% CI, 145.6- >9999, P<0.001), the CPS of grade 1 (OR, 5.71; 95\% CI, 1.67-19.5, P=0.006), grade 2 (OR, 11.4; 95\% CI, 2.46-52.4, $\mathrm{P}=0.002)$ and grade $3(\mathrm{OR}, 21.5 ; 95 \% \mathrm{CI}, 1.81-254.7, \mathrm{P}=0.015)$ were predictive for the development of NAION.
\end{abstract}

\title{
Discussion
}

Our study demonstrated increased C-IMT and higher prevalence of carotid artery plaque were found in middle-aged and elderly hypertensive patients with NAION compared to the control groups, indicating NAION may be associated with carotid artery atherosclerosis.

High-resolution carotid artery ultrasonography has been gaining acceptance as a non-invasive measure of preclinical atherosclerosis since the late 1980s [19]. Detecting carotid plaque formation and measuring C-IMT by ultrasonography is critical in the diagnosis of atherosclerosis. -Although Fry et al found development of anterior ischemic optic neuropathy (AION) is not associated with carotid artery atherosclerosis, their study was limited by a size of only 15 participants, 
undifferentiation of non-arteritic AION and arteritic AION and also carotid stenosis measurement at a mixture of carotid artery locations; furthermore, their definition of significant carotid stenosis was controversial [20]. In contrast, our study measured IMT of common carotid artery (C-IMT) and thickness of carotid artery plaque using high-resolution ultrasonography; these two parameters are widely used to diagnose atherosclerosis, which is consistent with our previously published study [8]. By comparing Hypertensive and Normal groups as controls, we also found that C-IMT was significantly thicker on the affected side of the NAION patients compared to the contralateral side as well as to the measurement in the control groups. The current study also demonstrated increased C-IMT was significantly associated with ipsilateral NAION. Furthermore, we established that CPS was much more severe in patients with NAION comparing with either the Hypertensive group or the Normal group. Carotid artery plaque grade 1 and grade 2 were significantly associated with NAION, supporting the observation made by Kim and colleagues [13].

Our study was also consistent with the conclusion made by Şahin $\mathrm{M}$ et al that atherosclerosis accompanying hypertension plays an important role in the pathogenesis of NAION [21]. It is widely believed that the development of NAION is a consequence of multiple factors, including systemic haemodynamic disorders and local anatomical factors $[6,22]$. In NAION, ischaemic infarction of the optic nerve head is secondary to poor perfusion of short posterior ciliary artery. Macro and micro vascular disorders play a key role in the pathogenesis of reduced perfusion [23]. 
Hypertension causes arterial endothelial dysfunction and disrupts release of vasoactive factors, predominantly nitric oxide (NO), where NO acts as a vasodilator [24].Therefore, dysfunctional endothelium may increase vascular tone, worsen vasodilation and cause vasoconstriction. Hypertension will further lead to intima-media thickening, stenosis, and formation of atherosclerotic plaques of carotid artery. This suggests the possibility of similar pathological changes in the context of intimal injury, thickening of muscular elastic layer, stenosis, increased vascular tone and impaired regulation of blood flow in the arteries supplying the optic disc. This ultimately results in hypoperfusion of the optic disc and hence development of NAION.

We also found that a higher level of HDL had a 'protective' effect in the development of NAION in hypertensive patients when comparing the NAION group with Hypertensive group athatightly higher level of HDL in the Hypertensive group than this is consistent with the statement made by Zotz and colleagues that a low level of HDL was associated with the development of NAION [25]. This phenomenon was not observed when comparing against the Normal group, hence further studies are needed for clarification.

There were some limitations to the present study. Firstly, we measured C-IMT and plaque formation from the common carotid artery instead of the retrobulbar artery, as 


\begin{abstract}
non-invasive method to reliably measure retrobulbar artery has yet been found. In addition, larger scale studies involving co-morbidities other than just hypertension and patients with races other than Chinese Asian would be helpful to further determine the pathogenic mechanisms of NAION. In the absence of follow-up of the subjects, we do not know whether or not these contralateral eyes of the NAION patients were at risk for developing NAION. Further studies are also needed to assess the change of carotid artery ultrasound findings as well as occurrence of NAION in the contralateral eye.
\end{abstract}

Our study concluded that C-IMT and carotid artery plaque were associated with NAION in hypertensive patients with NAION, suggesting that NAION might be associated with carotid artery atherosclerosis. This association may be due to the similar pathological changes occurring in the inner vascular wall of the carotid artery and the arteries supplying the optic nerve head. Screening C-IMT and CPS with carotid artery ultrasound might be useful in the evaluation of potential NAION, in particular among those patients with risk factors for carotid artery atherosclerosis.

\section{Disclosure}

Funding Department of Science and Technology of Guangdong Province provided financial support in the form of 2014A020212578 funding. The sponsor had no role in the design or conduct of this research.

Conflict of Interest All authors certify that they have no affiliations with or 14
Commented [ZHU8]: Reviewer 2, Comment 2.3

Commented [ZHU9]: Reviewer 1, Comment 1.1

Commented [ZHU10]: Reviewer 1, Comment 1.2 
involvement in any organization or entity with any financial interest (such as honoraria; educational grants; participation in speakers' bureaus; membership, employment, consultancies, stock ownership, or other equity interest; and expert testimony or patent-licensing arrangements), or non-financial interest (such as personal or professional relationships, affiliations, knowledge or beliefs) in the subject matter or materials discussed in this manuscript.

Ethical approval All procedures performed in studies involving human participants were in accordance with the ethical standards of the institutional and/or national research committee and with the 1964 Helsinki declaration and its later amendments or comparable ethical standards.

Informed consent Informed consent was obtained from all individual participants included in the study.

All authors certify that they have no involvement in any organization or entity with any financial interest.

Department of Science and Technology of Guangdong Province provided financial support in the form of 20141020212578 funding. The spensor had no role in the design-or conduct of this research.

\section{References}

1. Hayreh SS. (2009) Ischemic optic neuropathy. Prog Retin Eye Res 28:34-62.

2. Wang Y, Xu L, Jonas J.B. (2007) Frequency of Non-Arteritic Anterior Ischaemic Optic Neuropathy in Adult Chinese: The Beijing Eye Study. Br J Ophthalmol 91:401. 3. Arnold AC. (2003) Pathogenesis of nonarteritic anterior ischemic optic neuropathy. J Neuroophthalmol 23:157-63. 
4. Hayreh SS. (1997) Anterior ischemic optic neuropathy. Clin Neurosci 4:251-63.

5. Beck RW, Savino PJ, Repka MX, Schatz NJ, Sergott RC. (1984) Optic disk structure in anterior ischemic optic neuropathy. Ophthalmology 91:1334-7. 6. Hayreh SS, Joos KM, Podhajsky PA, Long CR. (1994) Systemic diseases associated with nonarteritic anterior ischemic optic neuropathy. Am J Ophthalmol 118:766-80.

7. Sanjari MS, Falavarjani KG, Mehrabani M, Ghiasian L, Zamani B. (2009) Retrobulbar haemodynamics and carotid wall thickness in patients with non-arteritic anterior ischaemic optic neuropathy. Br J Ophthalmol 93:638-40.

8. Zhu W, Cui M, Yao F, Liao R, Liu L. (2014) Retrobulbar and common carotid artery haemodynamics and carotid wall thickness in patients with non-arteritic anterior ischaemic optic neuropathy. Graefes Arch Clin Exp Ophthalmol 252: 1141-6. 9. Yao F, Wan P, Su Y, Liao R, Zhu W. (2016) Impaired systemic vascular endothelial function in patients with non-arteritic anterior ischaemic optic neuropathy. Graefes Arch Clin Exp Ophthalmol 254:977-81.

10. Nadar S, Blann AD, Lip GY. (2004) Endothelial dysfunction: methods of assessment and application to hypertension. Curr Pharm Des 10:3591-605

11. Deanfield JE, Halcox JP, Rabelink TJ. (2007) Endothelial function and dysfunction: testing and clinical relevance. Circulation 115: 1285-95

12. Grønholdt ML, Nordestgaard BG, Schroeder TV, Vorstrup S, Sillesen H. (2001) Ultrasonic Echolucent Carotid Plaques Predict Future Strokes. Circulation 104:68-73.

13. Kim SK, Volpe NJ, Stoltz RA. (2006) Contemporaneous retinal and optic nerve 
infarcts choroidal non-perfusion, and Hollenhorst Plaque: are these all embolic events? J Neuroophthalmol 26:113-6.

14. Leisser C. ( 2014 ) Are there differences between internal carotid artery and aortic arch plaques among patients with retinal artery occlusion and anterior ischaemic optic neuropathy? Klin Monbl Augenheilkd 231:1084-7.

15. Naqvi TZ, Lee MS. (2014) Carotid intima-media thickness and plaque in cardiovascular risk assessment. JACC Cardiovasc Imaging 7:1025-38.

16. Chambless LE, Heiss G, Folsom AR, et al. (1997) Association of coronary heart disease incidence with carotid arterial wall thickness and major risk $f$ actors: the Atherosclerosis Risk in Communities (ARIC) Study, 1987-1993. Am J Epidemiol $146: 483-94$.

17. Touboul PJ1, Hennerici MG, Meairs S, et al. (2012) Mannheim carotid intima-media thickness and plaque consensus (2004-2006-2011). An update on behalf of the advisory board of the $3 \mathrm{rd}$, 4thand 5th watching the risk symposia, at the 13 th, 15th and 20th European Stroke Conferences, Mannheim, Germany, 2004, Brussels, Belgium, 2006, and Hamburg, Germany, 2011. Cerebrovasc Dis 34:290-6.

18. Yerly P, Rodondi N, Viswanathan B, Riesen W, Vogt P, Bovet P. (2013) Association between conventional risk factors and different ultrasound-based markers of atherosclerosis atcarotid and femoral levels in a middle-aged population. Int $\mathbf{J}$ Cardiovasc Imaging 29:589-99.

19. Poli A, Tremoli E, Colombo A, Sirtori M, Pignoli P, Paoletti R. (1988) Ultrasonographic measurement of the common carotid artery wall thickness in 
hypercholesterolaemic subjects. A new model for the quantitation and follow up preclinical atherosclerosis in living human subjects. Atherosclerosis 70:253-61.

20. Fry CL, Carter JE, Kanter MC, Tegeler CH, Tuley MR. ( 1993) Anterior ischemic optic neuropathy is not associated with carotid artery atherosclerosis. Stroke 24:539-42.

21. Şahin M, Şahin A, Elbey B, Yüksel H, Türkcü FM, Cingü AK. (2016) Mean Platelet Volume in Patients with Nonarteritic Anterior Ischemic Optic Neuropathy. J Ophthalmol 2016:1-5.

22. Hayreh SS. (2013) Ischemic optic neuropathies - where are we now? Graefes Arch Clin Exp Ophthalmol 251:1873-84.

23. Salomon O, Huna-Baron R, Kurtz S, et al. (2013) Analysis of prothrombotic and vascular risk factors in patients with nonarteritic anterior ischemic optic neuropathy. Ophthalmology 106:739-42.

24. Deanfield JE, Halcox JP, Rabelink TJ. (2007) Endothelial function and dysfunction: testing and clinical relevance. Circulation 115:1285-95.

25. Zotz RB, Finger C, Scharf RE, Unsöld R. (2016) Associations between thrombophilic risk factors and determinants of atherosclerosis and inflammation in patients with non-arteritic anterior ischaemic optic neuropathy. Hamostaseologie 36:46-54. 
1

2

3

4

5

6

Figure

Fig. 1 Doppler imaging and the counterpart ipsilateral fundus photographs of a typical patient with unilateral non-arteritic anterior ischaemic optic neuropathy (NAION) in the left eye. a the intima-media thickness of common carotid artery (C-IMT) of the affected side; $\mathbf{b}$ the C-IMT of the healthy side; $\mathbf{c}$ the carotid artery plaque of the affected side, the arrow indicates the carotid artery plaque of maximum thickness; $\mathbf{d}$

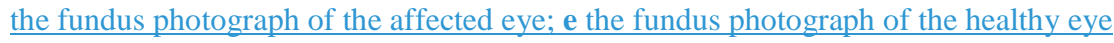


Table 1 Participant's characteristics of the patients with NAION and the controls (Data was presented as Mean (SD), otherwise as noted.)

\begin{tabular}{|c|c|c|c|c|c|c|}
\hline Characteristics & $\begin{array}{c}\text { All } \\
(n=192)\end{array}$ & $\begin{array}{c}\text { NAION } \\
(n=48,25 \%) \\
(1)\end{array}$ & $\begin{array}{c}\text { Hypertension } \\
(\mathrm{n}=\mathbf{4 6 , 2 4 \% )} \\
(2)\end{array}$ & $\begin{array}{l}\text { Normal } \\
(\mathrm{n}=98,51 \%) \\
(3)\end{array}$ & $\begin{array}{l}\text { P value } \\
\text { for } \\
\text { (1)vs.(2) } \dagger\end{array}$ & $\begin{array}{l}\text { P value } \\
\text { for } \\
\text { (1)vs.(3)† }\end{array}$ \\
\hline \multicolumn{7}{|l|}{ Clinical data } \\
\hline Age & $56.9(10.8)$ & $56.7(11.9)$ & $56.5(9.25)$ & $57.3(10.9)$ & 1.000 & 1.000 \\
\hline Male, n (\%) & $92(47.9)$ & $19(39.6)$ & $24(52.2)$ & $49(50.0)$ & 0.444 & 0.474 \\
\hline BMI & $23.1(3.00)$ & $23.6(3.35)$ & $22.8(2.74)$ & $23.0(2.93)$ & 0.328 & 0.443 \\
\hline SBP & $127.9(15.1)$ & $135.6(16.3)$ & $134.8(15.7)$ & $120.8(10.0)$ & 1.000 & $<0.001$ \\
\hline DBP & $73.5(8.05)$ & $74.9(7.96)$ & $75.9(8.21)$ & $71.7(7.68)$ & 1.000 & 0.046 \\
\hline \multicolumn{7}{|l|}{ Laboratory data } \\
\hline СHO & $5.16(0.86)$ & $4.93(0.93)$ & $5.26(0.66)$ & $5.22(0.89)$ & 0.129 & 0.122 \\
\hline LDL & $3.22(0.69)$ & $3.07(0.86)$ & $3.36(0.66)$ & $3.22(0.61)$ & 0.087 & 0.429 \\
\hline HDL & $1.29(0.31)$ & $1.24(0.31)$ & $1.39(0.30)$ & $1.26(0.31)$ & 0.034 & 1.000 \\
\hline TG & $1.33(0.59)$ & $1.42(0.61)$ & $1.30(0.56)$ & $1.30(0.59)$ & 0.593 & 0.502 \\
\hline FBG & $5.22(0.59)$ & $5.19(0.63)$ & $5.12(0.54)$ & $5.28(0.59)$ & 1.000 & 0.775 \\
\hline UA & $293.8(58.4)$ & $305.2(66.4)$ & $286.1(62.8)$ & $291.8(51.5)$ & 0.226 & 0.383 \\
\hline \multicolumn{7}{|l|}{ Vascular data } \\
\hline BD & $3.58(0.55)$ & $3.54(0.51)$ & $3.70(0.62)$ & $3.55(0.53)$ & 0.351 & 1.000 \\
\hline C-IMT* & $0.80(0.22)$ & $1.00(0.23)$ & $0.83(0.17)$ & $0.69(0.16)$ & $<0.001$ & $<0.001$ \\
\hline C-IMT§ & $0.76(0.18)$ & $0.83(0.19)$ & $0.83(0.17)$ & $0.69(0.16)$ & 1.000 & $<0.001$ \\
\hline CPS, n (\%) & & & & & 0.001 & $<0.001$ \\
\hline $\mathbf{0}$ & $123(64.1)$ & $13(27.1)$ & $31(67.4)$ & 79 (80.6) & & \\
\hline 1 & $36(18.7)$ & $16(33.3)$ & $7(15.2)$ & $13(13.3)$ & & \\
\hline 2 & $22(11.5)$ & $14(29.2)$ & $3(6.52)$ & $5(5.10)$ & & \\
\hline 3 & $11(5.73)$ & $5(10.4)$ & $5(10.9)$ & $1(1.02)$ & & \\
\hline
\end{tabular}

SD, Standard deviation; NAION, non-arteritic anterior ischaemic optic neuropathy; BMI, body mass index; BP, blood pressure; SBP, systolic blood pressure, DBP, diastolic blood pressure; CHO, cholesterol; HDL, high-density lipoprotein; LDL, low-density lipoprotein; TG, triglyceride; FBG, fasting blood glucose; UA, Uric Acid; BD, Baseline diameter; C-IMT, intima-media thickness of the common carotid artery; CPS, carotid artery plaque score * Data for the side with NAION was reported. $\S$ Data for the unaffected side of the NAION patient was reported.

$\dagger$ Logistic regression for sex, ordinal logistic regression for carotid artery plaque score and One-way ANOVA for other variables were used for multiple comparisons. The $\mathrm{P}$ values were presented with Bonferroni correction. 
Table 2 Multinomial logistic regression of potential factors on the presence of NAION compared with the Hypertension and Normal group

\begin{tabular}{|c|c|c|c|c|}
\hline \multirow[t]{2}{*}{ Variable } & \multicolumn{2}{|c|}{ Hypertension as Reference* } & \multicolumn{2}{|c|}{ Normal as Reference* } \\
\hline & OR $(95 \% \mathrm{CI})$ & $P$ value & OR $(95 \% \mathrm{CI})$ & $P$ value \\
\hline SBP & & & $1.07(1.03,1.12)$ & 0.001 \\
\hline HDL & $0.11(0.02,0.58)$ & 0.009 & & \\
\hline C-IMT $\dagger$ & $45.0(3.86,525.8)$ & 0.002 & $2351.4(145.6,>9999)$ & $<0.001$ \\
\hline \multicolumn{5}{|l|}{ CPS } \\
\hline 0 & Reference & & Reference & \\
\hline 1 & $3.78(1.15,12.4)$ & 0.028 & $5.71(1.67,19.5)$ & 0.006 \\
\hline 2 & $8.84(1.91,40.8)$ & 0.005 & $11.4(2.46,52.4)$ & 0.002 \\
\hline 3 & $2.66(0.56,12.6)$ & 0.218 & $21.5(1.81,254.7)$ & 0.015 \\
\hline
\end{tabular}

OR, Odds ratio; BMI, body mass index; BP, blood pressure; SBP, systolic blood pressure, DBP, diastolic blood pressure; CHO, cholesterol; HDL, high-density lipoprotein; LDL, low-density lipoprotein; TG, triglyceride; FBG, fasting blood glucose; UA, Uric Acid; BD, Baseline diameter; C-IMT, intima-media thickness of the common carotid artery; NAION, non-arteritic anterior ischaemic optic neuropathy; CPS, carotid artery plaque score $\dagger$ Data for the side with NAION was used.

* Variables with $\mathrm{P}<0.05$ in simple regression were included in the multiple regression model. 


\title{
Carotid artery intimal medial thickness and carotid artery plaques in hypertensive patients with non-arteritic anterior ischaemic optic neuropathy
}

\author{
Wenhui Zhu, MD ${ }^{1,2^{*}}$, Tingting Chen, MD ${ }^{1,2^{*}}$, Ling Jin, MS ${ }^{1}$, Haoyu Wang, BSc ${ }^{3}$, \\ Fengjuan Yao, MD, PhD ${ }^{4}$, Congyao Wang, MD¹, Qi Wang, $\mathrm{BSc}^{2}$, Nathan \\ Congdon, MD, MPH ${ }^{1.5}$ \\ 1. State Key Laboratory of Ophthalmology, Zhongshan Ophthalmic Center, Sun Yat-sen \\ University, Guangzhou, China, 510060
}

2. Department of Ophthalmology, The First Affiliated Hospital of Sun Yat-sen University, Guangzhou, China, 510080

3. School of Medicine, University of Manchester, Oxford Road, Manchester, United Kingdom M13 9PT

4. Department of Ultrasound, The First Affiliated Hospital of Sun Yat-sen University, Guangzhou, China, 510080

5. Centre for Public Health, Queen's University Belfast, Belfast BT12 6BJ, Northern Ireland

*Co-first authors

Corresponding author: Nathan Congdon,

Mailing address: State Key Laboratory of Ophthalmology, Zhongshan Ophthalmic Center, Sun Yat-sen University, 54 S. Xianlie Road, Guangzhou, People's Republic of China, 510060

E-mail: ncongdon1@gmail.com

Telephone: +86 (20) 87682342 


\section{Abstract}

Purpose: To assess the correlation of carotid artery intimal medial thickness (C-IMT) and carotid artery plaque score (CPS) of the common carotid artery with non-arteritic anterior ischemic optic neuropathy (NAION) in hypertensive patients.

Methods: This case-control study recruited 192 subjects. 48 patients had NAION with systemic hypertension, 46 had hypertension without visual complaints and 98 were normal controls. C-IMT and common carotid arterial plaque were measured by high-resolution vascular ultrasonography.

Results: High-density lipoprotein (HDL) in patients with NAION (1.24 \pm 0.31$)$ was significantly lower than that of the Hypertensive group $(1.39 \pm 0.30, \mathrm{P}=0.034)$. The C-IMT in the affected side of patients with NAION (1.00 \pm 0.23$)$ was significantly increased compared to the unaffected side $(0.83 \pm 0.19, \mathrm{P}<0.001)$, the Hypertensive group $(0.83 \pm 0.17, \mathrm{P}<0.001)$ and the Normal group $(0.69 \pm 0.16, \mathrm{P}<0.001)$. The presence of carotid artery plaque was more frequent in the patients with NAION, compared to either the Hypertensive group $(\mathrm{P}=0.001)$ or the Normal group $(\mathrm{P}<0.001)$. By multiple regression analysis, lower high-density lipoprotein (HDL) ( $\mathrm{P}=0.009)$, thicker C-IMT $(\mathrm{P}=0.002)$, CPS Grade $=1(\mathrm{P}=0.028)$ and Grade=2 $(\mathrm{P}=0.005)$ were associated with increased NAION risk, when the NAION group compared with the Hypertensive group $(\mathrm{OR}>1.0)$. Systolic blood pressure $(\mathrm{P}=0.001)$, thicker C-IMT $(\mathrm{P}<0.001)$, CPS Grade $=1(\mathrm{P}=0.006)$, Grade $=2(\mathrm{P}=0.002)$ and Grade $=3(\mathrm{P}=0.015)$ were associated with increased NAION risk, when the NAION group compared with the Normal group (OR>1.0). 
Conclusions: C-IMT and CPS were associated with NAION in hypertensive patients, suggesting that NAION might be associated with carotid artery atherosclerosis. This association may be due to similar pathological changes of the inner vascular walls in the carotid artery and the arteries supplying the optic nerve head.

Key words: Non-arteritic anterior ischaemic optic neuropathy; Intimal medial thickness; Carotid artery plaque; Doppler sonography 


\section{Introduction}

Non-arteritic anterior ischaemic optic neuropathy (NAION) is the commonest form of acute optic neuropathies occurring in the middle-aged and elderly population [1], with an estimated prevalence of 1 in 4,500 in Chinese population aged over 40 years according to the Beijing Eye Study [2]. Some specific aetiologies of NAION have been suggested, but the exact causal mechanism still remains unclear. NAION is widely believed to be a consequence of vascular insufficiency proceeding to ischaemia of the optic nerve head, and is characterized by acute, painless visual loss and visual field defects [3]. Many risk factors for NAION have been identified, including small, crowded discs and traditional cardiovascular risk factors (hypertension, diabetes mellitus, dyslipidemia, and coronary artery disease) [4-5]. Hypertension is the commonest vasculopathic risk factor for NAION patients, accounting for 47 to $49 \%$ of cases [6].

Sanjari et al using high-resolution ultrasonography revealed that the intima-media thickness of the common carotid artery (C-IMT) on the affected side of NAION was thicker than that of the contralateral healthy side [7], while our previous study found C-IMT was greater on the side affected by NAION compared to normal controls, but not different compared to the unaffected side of NAION patients [8].

Endothelium-dependent flow-mediated vasodilation (FMD) of the brachial artery is a 
validated, widely used and non-invasive measure in assessing overall endothelial function. Our previous study showed that dysfunctional endothelium (lower FMD) was associated with greater risk of NAION [9]. Dysfunctional endothelium may increase vascular tone and promote adhesion of monocytes and leucocytes as well as activation of platelets and formation of thrombus [10-11]. Grønholdt et al found a significant association between echolucent carotid artery plaque and embolic cerebrovascular accidents and suggested that the former could be used to predict the risk of developing stroke [12]. Kim et al reported in a case study that the presence of echolucent carotid artery plaque could be the embolic origin in causing NAION [13]. In addition, Leisser $\mathrm{C}$ found NAION patients had statistically significantly more frequent small plaques in the internal carotid artery [14]. However, the relationship between carotid artery plaque and NAION still remains unclear.

Our study was designed to assess C-IMT and carotid artery plaque of common carotid arteries in hypertensive patients with unilateral NAION and to evaluate their associations with NAION.

\section{Patients and Methods}

This study was approved by the Ethics Committee of Sun Yat-sen University, Guangzhou, China, written consent was provided by all study participants, and the tenets of the Declaration of Helsinki were followed throughout. 
Consecutive, consenting participants aged 36 to 79 years meeting the below inclusion criteria were recruited between March 2011 and September 2016 at Zhongshan Ophthalmic Centre (ZOC) and the First Affiliated Hospital of Sun Yat-sen University. Blood pressure, C-IMT, carotid artery plaques and fasting (> 8 hours) blood samples were obtained from these eligible patients.

Three patient groups were recruited including 1) NAION group (patients with both systemic hypertension [systolic blood pressure > $140 \mathrm{mmHg}$, diastolic blood pressure > $90 \mathrm{mmHg}$ or currently on antihypertensive medications] and unilateral NAION), 2) Hypertensive group (patients with systemic hypertension and no visual complaints) and 3) Normal group (healthy volunteers who were normotensive, never used antihypertensive medications and had no family history of vascular disease, or personal history of visual problems). Patients in the Hypertensive group and Normal group experienced no acute visual loss or impaired visual function at the time of recruitment and were enrolled at First Affiliated Hospital of Sun Yat-sen University. Patients from the NAION group were recruited from both ZOC and First Affiliated Hospital of Sun Yat-sen University and participants from all three groups had a full ophthalmological assessment with slit-lamp biomicroscopy and dilated funduscopic examination by a 78-diopter lens.

Exclusion criteria included: current pregnancy; current or recent (last 5 years) history of smoking; history of cardiovascular or cerebrovascular disease; diabetes mellitus; 
dyslipidaemia; alcohol abuse; high erythrocyte sedimentation rate (ESR) or a history suspicious for giant cell arteritis.

NAION was defined clinically as an acute presentation with painless loss of visual acuity in one eye, accompanied by relative afferent pupillary defect, optic disc oedema, visual field defect on automated perimetry and/or early filling defect of the disc by fluorescein angiography (FFA) in the affected eye, without evidence of other neurological, systemic or relevant ocular disease. Blood pressure was checked in a sitting position after patients rested for 10 minutes; we obtained three measures and the mean was calculated. All participants were asked to fast for at least 8 hours, not to drink coffee for at least 2 hours and to rest for 15 minutes prior to the ultrasound examination.

C-IMT was measured in both common carotid arteries $1 \mathrm{~cm}$ proximal to carotid artery bifurcation with a high-resolution vascular ultrasound probe (5-12 MHz, GE VIVID7, USA) in longitudinal section, using B-mode. C-IMT was calculated from the distance between two echogenic lines represented by the lumen-intima interface and the media-adventitia of the arterial wall respectively. C-IMT measurement of each side of carotid artery was repeated three times and the average carotid intima-media thickness was obtained for analysis. The result of each NAION patient was presented separately as 1) the average of the affected side (ipsilateral to the eye affected by NAION) and 2) the average of the unaffected side (contralateral to the eye affected by NAION). The 
result for the control groups was the average of bilateral measurements.

Carotid artery plaque was measured using the same ultrasound probe and defined as a focal thickening that encroaches into the lumen by $0.5 \mathrm{~mm}$, by $50 \%$ of the surrounding C-IMT or by C-IMT of $>1.5 \mathrm{~mm}$ according to the European Mannheim consensus [15-16]. All the plaques with maximum thickness in one carotid artery were measured regardless of plaque length and then the sum of these measurements were used to calculate carotid artery plaque score (CPS) [17]. Total CPS was calculated by adding the CPS from each carotid artery. Carotid artery plaque score was standardised as below: score of 0 when no plaques; score of 1 when both of the bilateral plaques were $<2 \mathrm{~mm}$; score of 2 when plaque from one carotid artery was $\geq 2$ $\mathrm{mm}$ and the other was $<2 \mathrm{~mm}$; and score of 3 when plaques from both carotid arteries were $\geq 2 \mathrm{~mm}[18]$. All the ultrasound measurements were performed and reported by the same expert operator, who was masked to the subject's medical condition.

\section{Statistical methods}

Results were presented as mean \pm standard deviation (SD) for continuous data and frequency (proportion) for categorical data. One-way ANOVA for continuous variables, logistic regression for sex and ordinal logistic regression for CPS were used for comparing the NAION group with the Hypertensive and Normal groups, and the $\mathrm{P}$ values of multiple comparisons underwent Bonferroni correction. Multinomial 
logistic regression was used to quantify the studied risk factors on NAION with Hypertensive and Normal groups as reference groups. Variables with $\mathrm{P}<.05$ in simple regression were included in the multiple regression model. Statistical analyses were performed using a commercially available software package (Stata 13.1, StataCorp, College Station TX, USA). Two-sided P<.05 was considered statistically significant for the main hypothesis.

\section{Results}

A total of 48, 46 and 98 patients were recruited in the NAION (mean [SD] age, 56.7 [11.9] years; 19 male [39.6\%]), Hypertensive (mean [SD] age, 56.5 [9.25] years; 24 male [52.2\%]) and Normal (mean [SD] age, 57.3 [10.9] years; 49 male [50.0\%]) groups respectively (Table 1). The mean duration for NAION was $12.2 \pm 3.6$ days and the mean interval between onset of NAION and variable measurements was $3.2 \pm 1.8$ days. Among 48 patients in the NAION group, 36 (75\%) were prescribed anti-hypertensive medications, which did not differ $(\mathrm{P}>0.999)$ from the proportion of patients who were receiving such medications in the Hypertensive group ( 34 of the 46 subjects [74\%]) (Data was not presented in table.) No patients were taking aspirin in any of the three groups.

No significant differences were observed with regard to age and gender between these groups and no difference was found between the three groups from laboratory 
parameters (Table 1). The systolic blood pressure (SBP) was significantly higher among patients in NAION group $(135.6 \pm 16.3)$ compared to the Normal group $(120.8 \pm 10.0, \mathrm{P}<0.001)$; however, no difference was detected between the NAION group and the Hypertensive group (134.8 $\pm 15.7, \mathrm{P}=1.00)$ (Table 1). The C-IMT on the

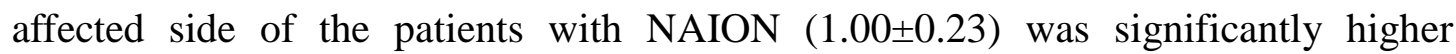
compared to the unaffected side $(0.83 \pm 0.19, \mathrm{P}<0.001)$. This measurement was also significantly higher than that in the Hypertensive group $(0.83 \pm 0.17, \mathrm{P}<0.001)$ and in the Normal group $(0.69 \pm 0.16, \mathrm{P}<0.001)$. The C-IMT of the unaffected side of NAION patients was not different from that of the Hypertensive group $(\mathrm{P}=1.000)$, however, it was significantly higher compared to that of healthy normal subjects $(0.83 \pm 0.19$ vs. $0.69 \pm 0.16, \mathrm{P}<0.001)$. CPS was more frequent in patients with NAION, comparing to either the Hypertensive group $(\mathrm{P}=0.001)$ or the Normal group $(\mathrm{P}<0.001)$.

Figure 1 shows Doppler imaging and the ipsilateral fundus photographs of a typical patient with unilateral NAION, including the images of the bilateral C-IMT, carotid artery plaque of maximum thickness, and bilateral fundus photographs.

Table 2 presented the multiple regression analysis of potential risk factors for NAION group compared with Hypertensive and Normal groups. Our results showed that when comparing with Hypertension group, thicker C-IMT (OR, 28.4; 95\% CI, 1.74- 464.5, $\mathrm{P}=0.002)$, the carotid artery plaques of grade $1(\mathrm{OR}, 3.78 ; 95 \% \mathrm{CI}, 1.15-12.4, \mathrm{P}=0.028)$ and grade $2(\mathrm{OR}, 8.84 ; 95 \% \mathrm{CI}, 1.91-40.8, \mathrm{P}=0.005)$ were predictive for the 
development of NAION; whereas higher level of high-density lipoprotein (HDL) (OR, $0.11 ; 95 \% \mathrm{CI}, 0.02-0.58, \mathrm{P}=0.009)$ were associated with lower risk of NAION. While comparing with Normal group, higher SBP (OR, 1.07; 95\% CI, 1.03-1.12, $\mathrm{P}=0.001)$, thicker C-IMT (OR, 2351.4; 95\% CI, 145.6- >9999, P<0.001), the CPS of grade 1 (OR, 5.71; 95\% CI, 1.67-19.5, P=0.006), grade 2 (OR, 11.4; 95\% CI, 2.46-52.4, $\mathrm{P}=0.002)$ and grade $3(\mathrm{OR}, 21.5 ; 95 \% \mathrm{CI}, 1.81-254.7, \mathrm{P}=0.015)$ were predictive for the development of NAION.

\section{Discussion}

Our study demonstrated increased C-IMT and higher prevalence of carotid artery plaque were found in middle-aged and elderly hypertensive patients with NAION compared to the control groups, indicating NAION may be associated with carotid artery atherosclerosis.

High-resolution carotid artery ultrasonography has been gaining acceptance as a non-invasive measure of preclinical atherosclerosis since the late 1980s [19]. Detecting carotid plaque formation and measuring C-IMT by ultrasonography is critical in the diagnosis of atherosclerosis. Although Fry et al found development of anterior ischemic optic neuropathy (AION) is not associated with carotid artery atherosclerosis, their study was limited by a size of only 15 participants, undifferentiation of non-arteritic AION and arteritic AION and also carotid stenosis measurement at a mixture of carotid artery locations; furthermore, their definition of 
significant carotid stenosis was controversial [20]. In contrast, our study measured IMT of common carotid artery (C-IMT) and thickness of carotid artery plaque using high-resolution ultrasonography; these two parameters are widely used to diagnose atherosclerosis, which is consistent with our previously published study [8]. By comparing Hypertensive and Normal groups as controls, we also found that C-IMT was significantly thicker on the affected side of the NAION patients compared to the contralateral side as well as to the measurement in the control groups. The current study also demonstrated increased C-IMT was significantly associated with ipsilateral NAION. Furthermore, we established that CPS was much more severe in patients with NAION comparing with either the Hypertensive group or the Normal group. Carotid artery plaque grade 1 and grade 2 were significantly associated with NAION, supporting the observation made by Kim and colleagues [13].

Our study was also consistent with the conclusion made by Şahin $\mathrm{M}$ et al that atherosclerosis accompanying hypertension plays an important role in the pathogenesis of NAION [21]. It is widely believed that the development of NAION is a consequence of multiple factors, including systemic haemodynamic disorders and local anatomical factors [6, 22]. In NAION, ischaemic infarction of the optic nerve head is secondary to poor perfusion of short posterior ciliary artery. Macro and micro vascular disorders play a key role in the pathogenesis of reduced perfusion [23]. Hypertension causes arterial endothelial dysfunction and disrupts release of vasoactive factors, predominantly nitric oxide (NO), where $\mathrm{NO}$ acts as a vasodilator 
[24].Therefore, dysfunctional endothelium may increase vascular tone, worsen vasodilation and cause vasoconstriction. Hypertension will further lead to intima-media thickening, stenosis, and formation of atherosclerotic plaques of carotid artery. This suggests the possibility of similar pathological changes in the context of intimal injury, thickening of muscular elastic layer, stenosis, increased vascular tone and impaired regulation of blood flow in the arteries supplying the optic disc. This ultimately results in hypoperfusion of the optic disc and hence development of NAION.

We also found slightly higher level of HDL in the Hypertensive group than in the NAION Group, which might indicate that HDL is a marker for good outcomes; this is consistent with the statement made by Zotz and colleagues that a low level of HDL was associated with the development of NAION [25]. This phenomenon was not observed when comparing against the Normal group, hence further studies are needed for clarification.

There were some limitations to the present study. Firstly, we measured C-IMT and plaque formation from the common carotid artery instead of the retrobulbar artery, as non-invasive method to reliably measure retrobulbar artery has yet been found. In addition, larger scale studies involving co-morbidities other than just hypertension and patients with races other than Chinese Asian would be helpful to further determine the pathogenic mechanisms of NAION. In the absence of follow-up of the 
subjects, we do not know whether or not these contralateral eyes of the NAION patients were at risk for developing NAION. Further studies are also needed to assess the change of carotid artery ultrasound findings as well as occurrence of NAION in the contralateral eye.

Our study concluded that C-IMT and carotid artery plaque were associated with NAION in hypertensive patients with NAION, suggesting that NAION might be associated with carotid artery atherosclerosis. This association may be due to the similar pathological changes occurring in the inner vascular wall of the carotid artery and the arteries supplying the optic nerve head. Screening C-IMT and CPS with carotid artery ultrasound might be useful in the evaluation of potential NAION, in particular among those patients with risk factors for carotid artery atherosclerosis.

\section{Disclosure}

Funding Department of Science and Technology of Guangdong Province provided financial support in the form of 2014A020212578 funding. The sponsor had no role in the design or conduct of this research.

Conflict of Interest All authors certify that they have no affiliations with or involvement in any organization or entity with any financial interest (such as honoraria; educational grants; participation in speakers' bureaus; membership, employment, consultancies, stock ownership, or other equity interest; and expert testimony or patent-licensing arrangements), or non-financial interest (such as 
personal or professional relationships, affiliations, knowledge or beliefs) in the subject matter or materials discussed in this manuscript.

Ethical approval All procedures performed in studies involving human participants were in accordance with the ethical standards of the institutional and/or national research committee and with the 1964 Helsinki declaration and its later amendments or comparable ethical standards.

Informed consent Informed consent was obtained from all individual participants included in the study.

\section{References}

1. Hayreh SS. (2009) Ischemic optic neuropathy. Prog Retin Eye Res 28:34-62.

2. Wang Y, Xu L, Jonas J.B. (2007) Frequency of Non-Arteritic Anterior Ischaemic Optic Neuropathy in Adult Chinese: The Beijing Eye Study. Br J Ophthalmol 91:401.

3. Arnold AC. (2003) Pathogenesis of nonarteritic anterior ischemic optic neuropathy. J Neuroophthalmol 23:157-63.

4. Hayreh SS. (1997) Anterior ischemic optic neuropathy. Clin Neurosci 4:251-63.

5. Beck RW, Savino PJ, Repka MX, Schatz NJ, Sergott RC. (1984) Optic disk structure in anterior ischemic optic neuropathy. Ophthalmology 91:1334-7.

6. Hayreh SS, Joos KM, Podhajsky PA, Long CR. (1994) Systemic diseases associated with nonarteritic anterior ischemic optic neuropathy. Am J Ophthalmol 118:766-80.

7. Sanjari MS, Falavarjani KG, Mehrabani M, Ghiasian L, Zamani B. (2009) Retrobulbar haemodynamics and carotid wall thickness in patients with non-arteritic 
anterior ischaemic optic neuropathy. Br J Ophthalmol 93:638-40.

8. Zhu W, Cui M, Yao F, Liao R, Liu L. (2014) Retrobulbar and common carotid artery haemodynamics and carotid wall thickness in patients with non-arteritic anterior ischaemic optic neuropathy. Graefes Arch Clin Exp Ophthalmol 252: 1141-6. 9. Yao F, Wan P, Su Y, Liao R, Zhu W. (2016) Impaired systemic vascular endothelial function in patients with non-arteritic anterior ischaemic optic neuropathy. Graefes Arch Clin Exp Ophthalmol 254:977-81.

10. Nadar S, Blann AD, Lip GY. (2004) Endothelial dysfunction: methods of assessment and application to hypertension. Curr Pharm Des 10:3591-605

11. Deanfield JE, Halcox JP, Rabelink TJ. (2007) Endothelial function and dysfunction: testing and clinical relevance. Circulation 115: 1285-95

12. Grønholdt ML, Nordestgaard BG, Schroeder TV, Vorstrup S, Sillesen H. (2001) Ultrasonic Echolucent Carotid Plaques Predict Future Strokes. Circulation 104:68-73. 13. Kim SK, Volpe NJ, Stoltz RA. (2006) Contemporaneous retinal and optic nerve infarcts choroidal non-perfusion, and Hollenhorst Plaque: are these all embolic events? J Neuroophthalmol 26:113-6.

14. Leisser C. ( 2014 ) Are there differences between internal carotid artery and aortic arch plaques among patients with retinal artery occlusion and anterior ischaemic optic neuropathy? Klin Monbl Augenheilkd 231:1084-7.

15. Naqvi TZ, Lee MS. (2014) Carotid intima-media thickness and plaque in cardiovascular risk assessment. JACC Cardiovasc Imaging 7:1025-38.

16. Chambless LE, Heiss G, Folsom AR, et al. (1997) Association of coronary heart 
disease incidence with carotid arterial wall thickness and major risk $\mathrm{f}$ actors: the Atherosclerosis Risk in Communities (ARIC) Study, 1987-1993. Am J Epidemiol 146:483-94.

17. Touboul PJ1, Hennerici MG, Meairs S, et al. (2012) Mannheim carotid intima-media thickness and plaque consensus (2004-2006-2011). An update on behalf of the advisory board of the 3rd, 4thand 5th watching the risk symposia, at the 13th, 15th and 20th European Stroke Conferences, Mannheim, Germany, 2004, Brussels, Belgium, 2006, and Hamburg, Germany, 2011. Cerebrovasc Dis 34:290-6.

18. Yerly P, Rodondi N, Viswanathan B, Riesen W, Vogt P, Bovet P. (2013) Association between conventional risk factors and different ultrasound-based markers of atherosclerosis atcarotid and femoral levels in a middle-aged population. Int $\mathbf{J}$ Cardiovasc Imaging 29:589-99.

19. Poli A, Tremoli E, Colombo A, Sirtori M, Pignoli P, Paoletti R. (1988) Ultrasonographic measurement of the common carotid artery wall thickness in hypercholesterolaemic subjects. A new model for the quantitation and follow up preclinical atherosclerosis in living human subjects. Atherosclerosis 70:253-61.

20. Fry CL, Carter JE, Kanter MC, Tegeler CH, Tuley MR. ( 1993) Anterior ischemic optic neuropathy is not associated with carotid artery atherosclerosis. Stroke 24:539-42.

21. Şahin M, Şahin A, Elbey B, Yüksel H, Türkcü FM, Cingü AK. (2016) Mean Platelet Volume in Patients with Nonarteritic Anterior Ischemic Optic Neuropathy. J Ophthalmol 2016:1-5. 
22. Hayreh SS. (2013) Ischemic optic neuropathies - where are we now? Graefes Arch Clin Exp Ophthalmol 251:1873-84.

23. Salomon O, Huna-Baron R, Kurtz S, et al. (2013) Analysis of prothrombotic and vascular risk factors in patients with nonarteritic anterior ischemic optic neuropathy. Ophthalmology 106:739-42.

24. Deanfield JE, Halcox JP, Rabelink TJ. (2007) Endothelial function and dysfunction: testing and clinical relevance. Circulation 115:1285-95.

25. Zotz RB, Finger C, Scharf RE, Unsöld R. (2016) Associations between thrombophilic risk factors and determinants of atherosclerosis and inflammation in patients with non-arteritic anterior ischaemic optic neuropathy. Hamostaseologie $36: 46-54$.

\section{Figure}

Fig. 1 Doppler imaging and the ipsilateral fundus photographs of a typical patient with unilateral non-arteritic anterior ischaemic optic neuropathy (NAION) in the left eye. a the intima-media thickness of common carotid artery (C-IMT) of the affected side; $\mathbf{b}$ the C-IMT of the healthy side; $\mathbf{c}$ the carotid artery plaque of the affected side, the arrow indicates the carotid artery plaque of maximum thickness; $\mathbf{d}$ the fundus photograph of the affected eye; $\mathbf{e}$ the fundus photograph of the healthy eye 
Table 1 Participant's characteristics of the patients with NAION and the controls (Data was presented as Mean (SD), otherwise as noted.)

\begin{tabular}{|c|c|c|c|c|c|c|}
\hline Characteristics & $\begin{array}{c}\text { All } \\
(n=192)\end{array}$ & $\begin{array}{c}\text { NAION } \\
(n=48,25 \%) \\
(1)\end{array}$ & $\begin{array}{l}\text { Hypertension } \\
(\mathrm{n}=\mathbf{4 6 , 2 4 \% )} \\
(2)\end{array}$ & $\begin{array}{l}\text { Normal } \\
(\mathrm{n}=98,51 \%) \\
(3)\end{array}$ & $\begin{array}{l}\text { P value } \\
\text { for } \\
\text { (1)vs.(2) } \dagger\end{array}$ & $\begin{array}{l}\text { P value } \\
\text { for } \\
\text { (1)vs.(3) }\end{array}$ \\
\hline \multicolumn{7}{|l|}{ Clinical data } \\
\hline Age & $56.9(10.8)$ & $56.7(11.9)$ & $56.5(9.25)$ & $57.3(10.9)$ & 1.000 & 1.000 \\
\hline Male, n (\%) & $92(47.9)$ & $19(39.6)$ & $24(52.2)$ & $49(50.0)$ & 0.444 & 0.474 \\
\hline BMI & $23.1(3.00)$ & $23.6(3.35)$ & $22.8(2.74)$ & $23.0(2.93)$ & 0.328 & 0.443 \\
\hline SBP & $127.9(15.1)$ & $135.6(16.3)$ & $134.8(15.7)$ & $120.8(10.0)$ & 1.000 & $<0.001$ \\
\hline DBP & $73.5(8.05)$ & $74.9(7.96)$ & $75.9(8.21)$ & $71.7(7.68)$ & 1.000 & 0.046 \\
\hline \multicolumn{7}{|l|}{ Laboratory data } \\
\hline $\mathrm{CHO}$ & $5.16(0.86)$ & $4.93(0.93)$ & $5.26(0.66)$ & $5.22(0.89)$ & 0.129 & 0.122 \\
\hline LDL & $3.22(0.69)$ & $3.07(0.86)$ & $3.36(0.66)$ & $3.22(0.61)$ & 0.087 & 0.429 \\
\hline HDL & $1.29(0.31)$ & $1.24(0.31)$ & $1.39(0.30)$ & $1.26(0.31)$ & 0.034 & 1.000 \\
\hline TG & $1.33(0.59)$ & $1.42(0.61)$ & $1.30(0.56)$ & $1.30(0.59)$ & 0.593 & 0.502 \\
\hline FBG & $5.22(0.59)$ & $5.19(0.63)$ & $5.12(0.54)$ & $5.28(0.59)$ & 1.000 & 0.775 \\
\hline UA & 293.8(58.4) & $305.2(66.4)$ & $286.1(62.8)$ & 291.8(51.5) & 0.226 & 0.383 \\
\hline \multicolumn{7}{|l|}{ Vascular data } \\
\hline BD & $3.58(0.55)$ & $3.54(0.51)$ & $3.70(0.62)$ & $3.55(0.53)$ & 0.351 & 1.000 \\
\hline C-IMT* & $0.80(0.22)$ & $1.00(0.23)$ & $0.83(0.17)$ & $0.69(0.16)$ & $<0.001$ & $<0.001$ \\
\hline C-IMT\$ & $0.76(0.18)$ & $0.83(0.19)$ & $0.83(0.17)$ & $0.69(0.16)$ & 1.000 & $<0.001$ \\
\hline CPS, n (\%) & & & & & 0.001 & $<0.001$ \\
\hline $\mathbf{0}$ & $123(64.1)$ & $13(27.1)$ & $31(67.4)$ & 79 (80.6) & & \\
\hline 1 & $36(18.7)$ & $16(33.3)$ & $7(15.2)$ & $13(13.3)$ & & \\
\hline 2 & $22(11.5)$ & $14(29.2)$ & $3(6.52)$ & $5(5.10)$ & & \\
\hline 3 & $11(5.73)$ & $5(10.4)$ & $5(10.9)$ & $1(1.02)$ & & \\
\hline
\end{tabular}

$\mathrm{SD}$, Standard deviation; NAION, non-arteritic anterior ischaemic optic neuropathy; BMI, body mass index; BP, blood pressure; SBP, systolic blood pressure, DBP, diastolic blood pressure; CHO, cholesterol; HDL, high-density lipoprotein; LDL, low-density lipoprotein; TG, triglyceride; FBG, fasting blood glucose; UA, Uric Acid; BD, Baseline diameter; C-IMT, intima-media thickness of the common carotid artery; CPS, carotid artery plaque score * Data for the side with NAION was reported.

$\S$ Data for the unaffected side of the NAION patient was reported.

$\uparrow$ Logistic regression for sex, ordinal logistic regression for carotid artery plaque score and One-way ANOVA for other variables were used for multiple comparisons. The $\mathrm{P}$ values were presented with Bonferroni correction. 
Table 2 Multinomial logistic regression of potential factors on the presence of NAION compared with the Hypertension and Normal group

\begin{tabular}{|c|c|c|c|c|}
\hline \multirow[t]{2}{*}{ Variable } & \multicolumn{2}{|c|}{ Hypertension as Reference* } & \multicolumn{2}{|c|}{ Normal as Reference* } \\
\hline & OR $(95 \% \mathrm{CI})$ & $P$ value & OR $(95 \%$ CI $)$ & $P$ value \\
\hline SBP & & & $1.07(1.03,1.12)$ & 0.001 \\
\hline HDL & $0.11(0.02,0.58)$ & 0.009 & & \\
\hline C-IMT $\dagger$ & $45.0(3.86,525.8)$ & 0.002 & $2351.4(145.6,>9999)$ & $<0.001$ \\
\hline \multicolumn{5}{|l|}{ CPS } \\
\hline 0 & Reference & & Reference & \\
\hline 1 & $3.78(1.15,12.4)$ & 0.028 & $5.71(1.67,19.5)$ & 0.006 \\
\hline 2 & $8.84(1.91,40.8)$ & 0.005 & $11.4(2.46,52.4)$ & 0.002 \\
\hline 3 & $2.66(0.56,12.6)$ & 0.218 & $21.5(1.81,254.7)$ & 0.015 \\
\hline
\end{tabular}

OR, Odds ratio; BMI, body mass index; BP, blood pressure; SBP, systolic blood pressure, DBP, diastolic blood pressure; CHO, cholesterol; HDL, high-density lipoprotein; LDL, low-density lipoprotein; TG, triglyceride; FBG, fasting blood glucose; UA, Uric Acid; BD, Baseline diameter; C-IMT, intima-media thickness of the common carotid artery; NAION, non-arteritic anterior ischaemic optic neuropathy; CPS, carotid artery plaque score $\dagger$ Data for the side with NAION was used.

* Variables with $\mathrm{P}<0.05$ in simple regression were included in the multiple regression model. 


\section{v}

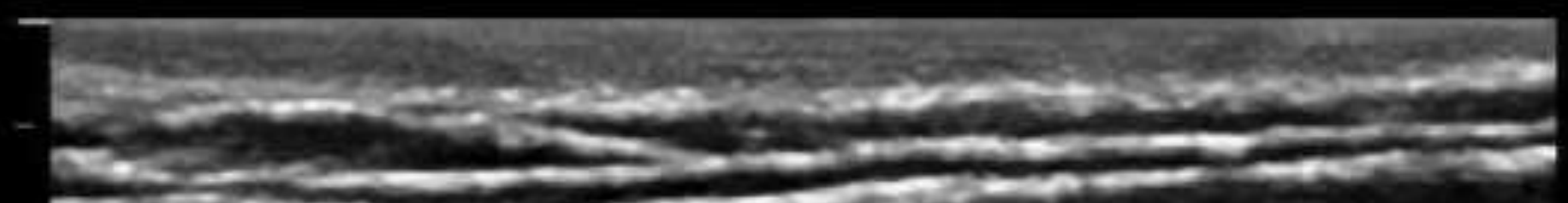

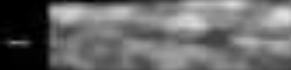

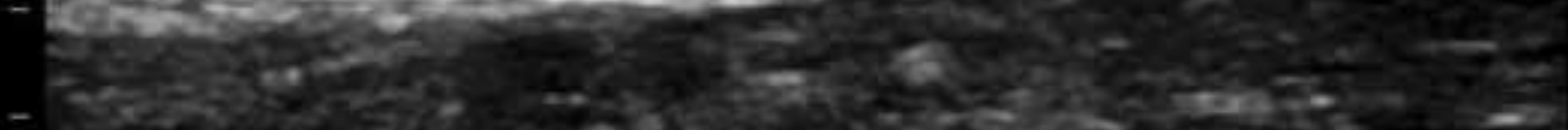

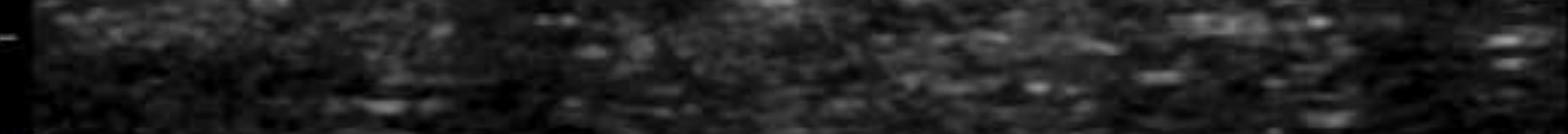

$x_{1-}$

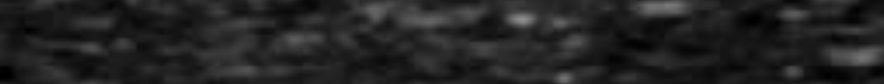

L

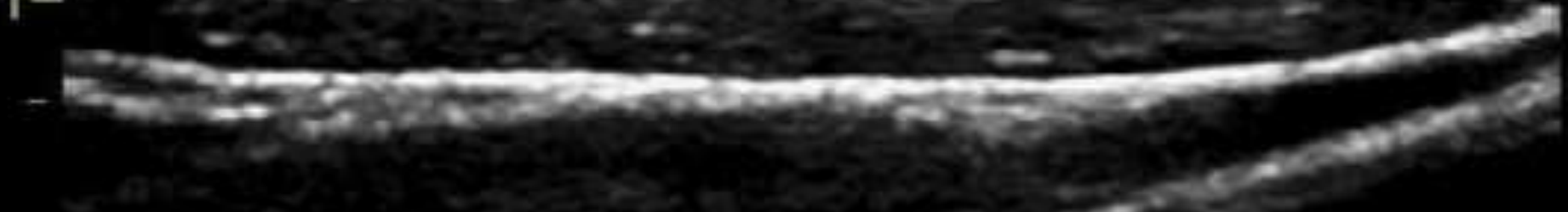

$\mathbf{x}$

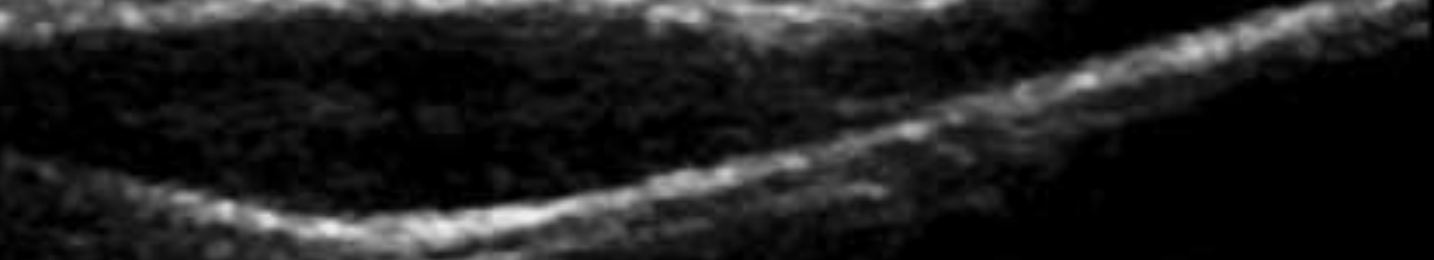

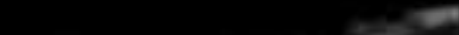

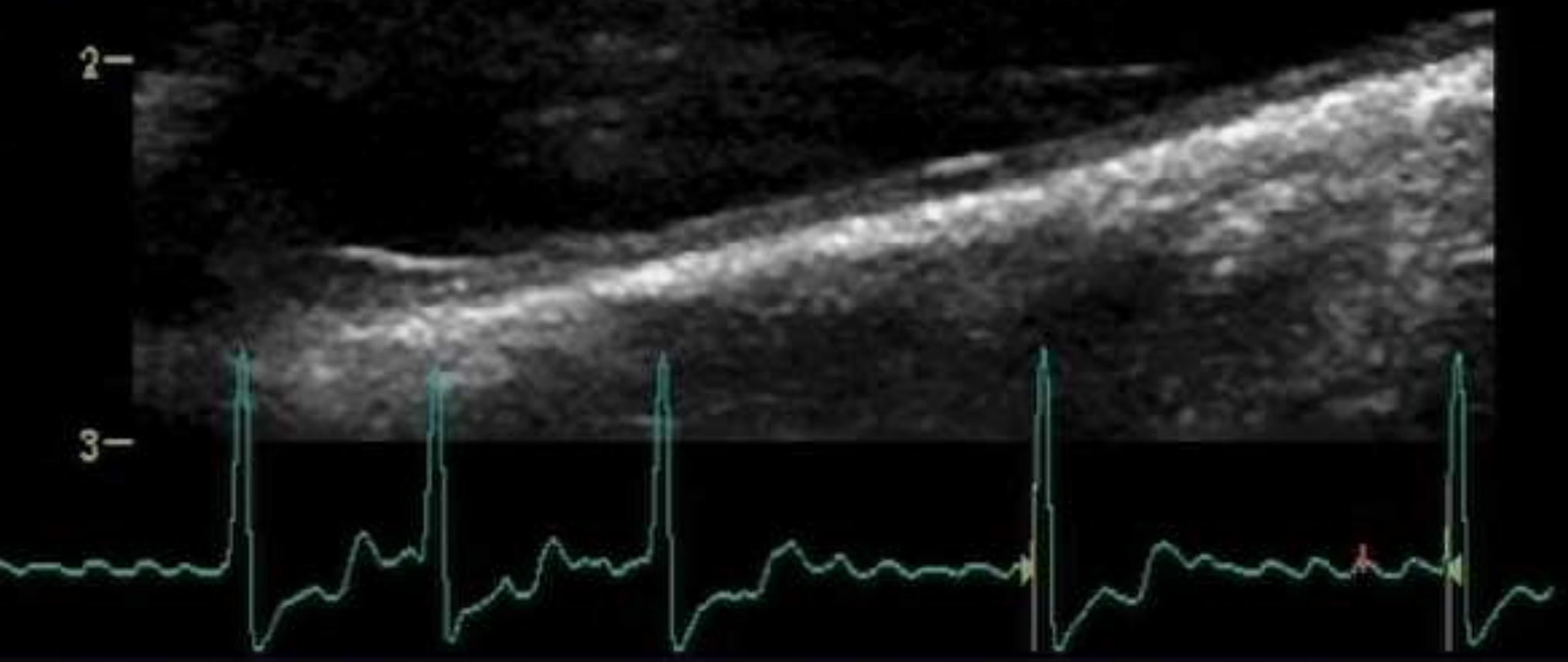

a 


\section{\begin{tabular}{|l|l|}
\hline $2 L$ & $0.08 \mathrm{~cm}$ \\
\hline $1 \mathrm{~L}$ & $0.59 \mathrm{~cm}$ \\
\hline
\end{tabular} 1}

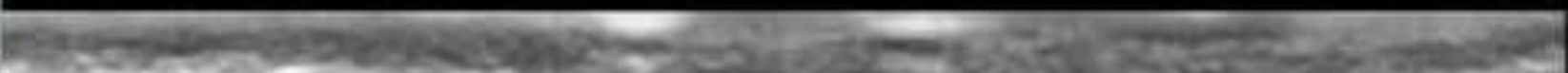

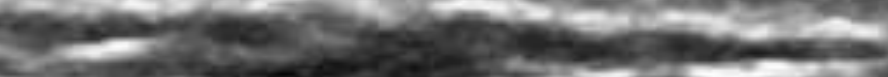

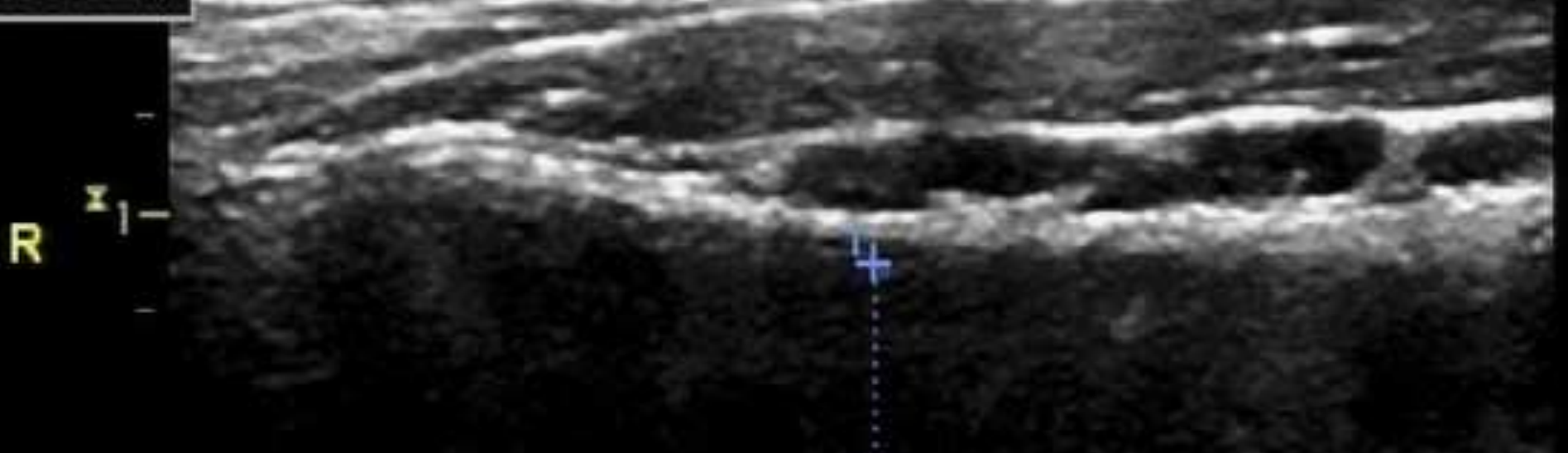

I

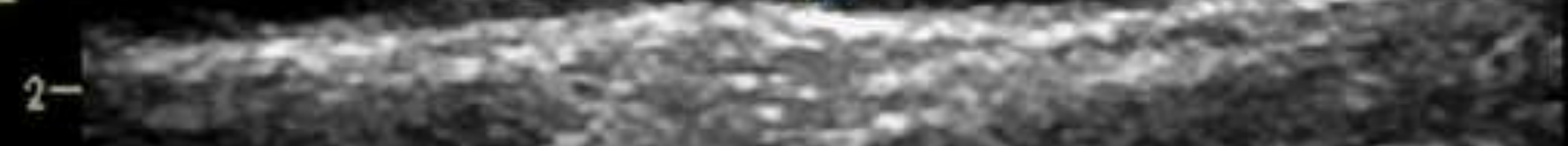

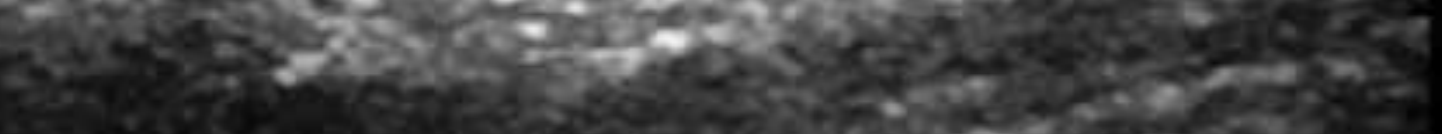




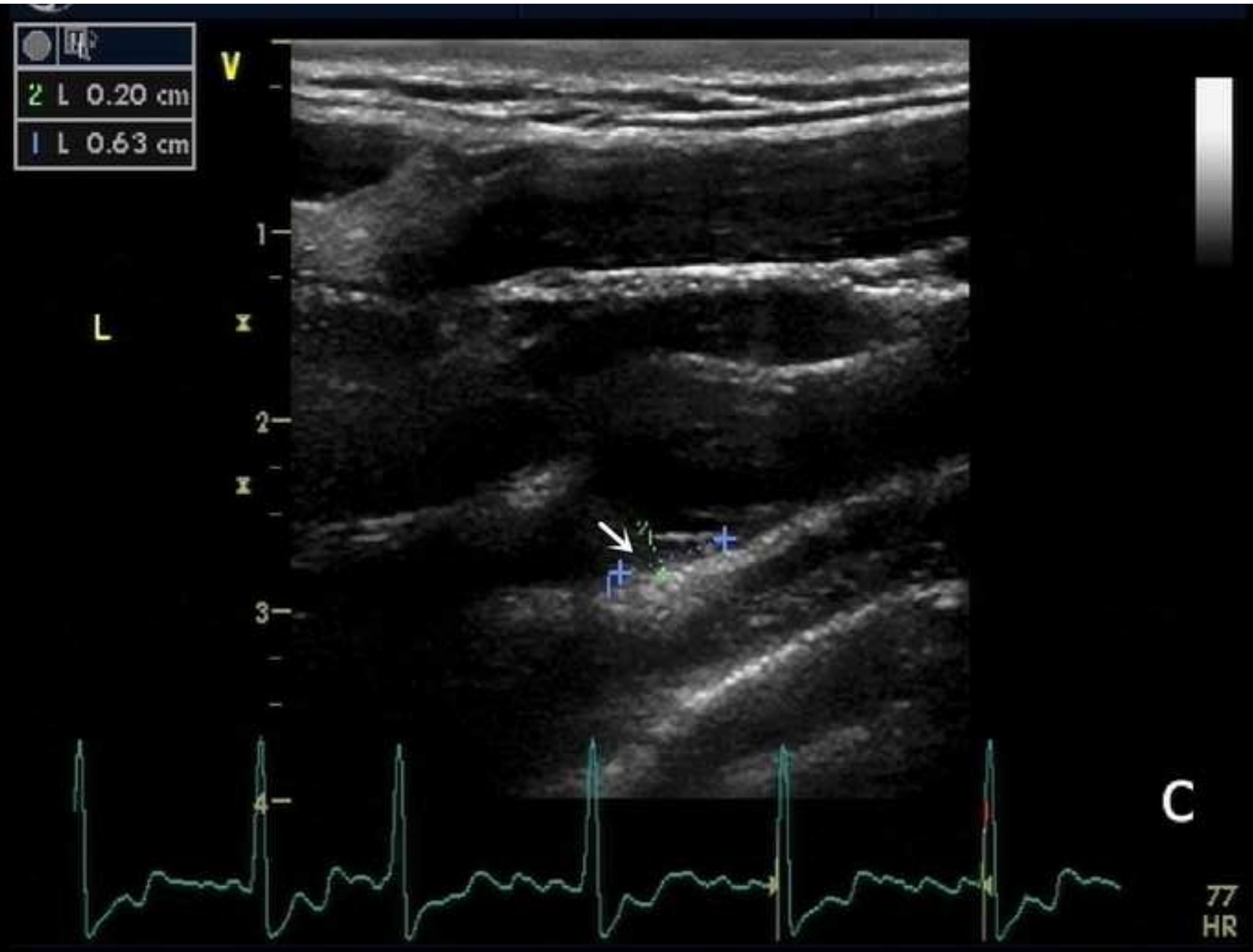


Figure e

Click here to download Figure healthy eye -e.jpg $\underline{\underline{ \pm}}$
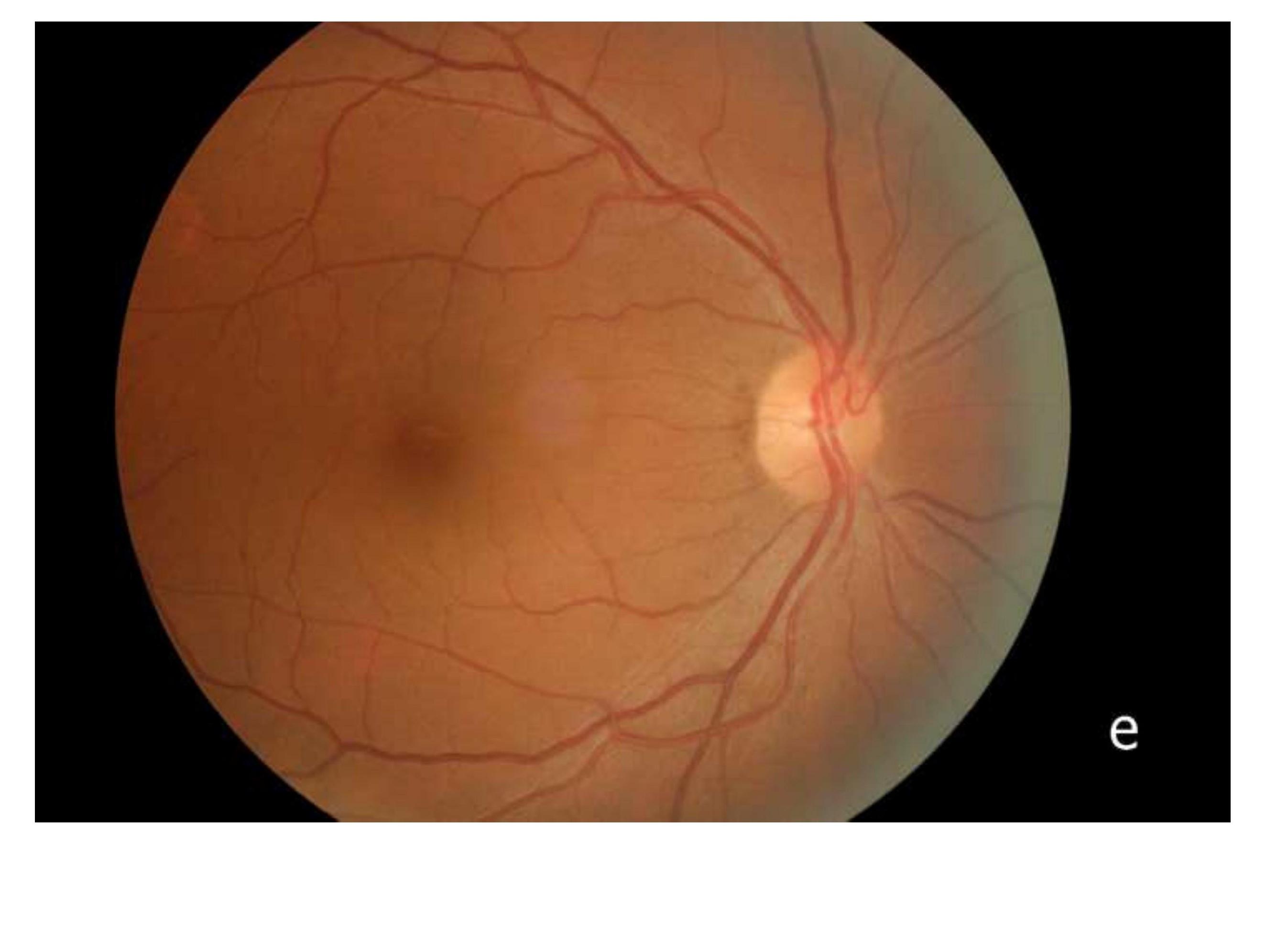